\title{
Синтез и фотолюминесценция наноразмерных структур на основе сульфидов цинка, кадмия и марганца в полиакрилатной матрице
}

\author{
(C) А.А. Исаева, В.П. Смагин \\ Алтайский государственный университет, \\ 656049 Барнаул, Россия \\ ฯ E-mail: smaginV@yandex.ru
}

Поступила в Редакцию 29 июня 2020 г.

В окончательной редакции 20 июля 2020 г.

Принята к публикации 27 июля 2020 г.

\begin{abstract}
Исследована фотолюминесценция наноразмерных структур на основе сульфидов цинка, кадмия и марганца в зависимости от условий синтеза и легирования в среде (поли)метилметакрилата (ПММА). Возбуждение фотолюминесценции связано с межзонным переходом электронов в полупроводниковой структуре, поглощением энергии оптического излучения дефектами структуры кристаллов, а также с переносом энергии на возбужденные уровни энергии ионов $\mathrm{Mn}^{2+}$. Люминесценция происходит в результате рекомбинационных процессов на уровнях дефектов структуры преимущественно на поверхности частиц и ${ }^{4} T_{1} \rightarrow{ }^{6} A_{1}$ переходов электронов между собственными уровнями энергии ионов $\mathrm{Mn}^{2+}$. На основании изменений в спектрах фотолюминесценции и возбуждения фотолюминесценции композиций ПММА/( $\mathrm{Zn}, \mathrm{Cd}, \mathrm{Mn}) \mathrm{S}$ высказаны предположения о структуре частиц. Показано, что на их фотолюминесценцию влияет распределение ионов $\mathrm{Mn}^{2+}$ в структуре слоев и на поверхности частиц.
\end{abstract}

Ключевые слова: многослойные квантовые точки, коллоидный синтез, сульфид цинка, сульфид кадмия, легирование, марганец, полиметилметакрилат, композиты, фотолюминесценция.

DOI: 10.21883/FTP.2020.12.50232.9475

\section{1. Введение}

Квантовые точки (КТ) находят широкое применение в оптоэлектронике, светотехнике, биологии, медицине. Для улучшения их оптических характеристик применяются различные технологии нанесения дополнительного слоя полупроводника на поверхность сформированной частицы [1-8]. Выделяют несколько типов наноразмерных структур „ядро/оболочка“ $[1,5,6,8-10]$.

Одним из способов минимизации напряжений в пограничном слое между ядром и оболочкой при несоответствии их кристаллографических параметров является формирование промежуточного слоя. Для этого реализуются различные варианты чередования полупроводников, различающихся шириной запрещенной зоны [3,8-11].

Для синтеза простых КТ и многослойных КТ (МКТ), как и для объемных кристаллических люминофоров, широко применяются полупроводники группы $\mathrm{A}^{\mathrm{II}} \mathrm{B}^{\mathrm{VI}}$ [12-21]. Впервые в качестве „адаптеров несоответствий решетки“ в системах „ядро/ оболочка/оболочка“ были применены $\mathrm{CdS}$ или $\mathrm{ZnSe}$ в системе $\mathrm{CdSe} / \mathrm{ZnS}[22,23]$. Примерами подобных структур также являются нанокристаллы $\mathrm{CdS} / \mathrm{HgS} / \mathrm{CdS}$ [8], $\mathrm{ZnS} / \mathrm{CdS} / \mathrm{ZnS}$ [11]. Большинство многослойных структур синтезированы методами ионного наслаивания на подложке $[24,25]$ и химическим осаждением из растворов $[11,26-29]$.

Послойное легирование многослойных структур можно рассматривать в качестве одного из способов „сглаживания“ несоответствий кристаллических решеток по- лупроводников на границе слоев, а также как способ формирования предсказуемой энергетической диаграммы каждого слоя и частицы в целом посредством формирования дефектов в объеме кристаллов каждого слоя и на их поверхности [20,30-35]. Кроме того, в легированных полупроводниках кроме рекомбинационной наблюдается внутризонная люминесценция [12,19]. Она связана с эмиссионными переходами электронов между собственными уровнями энергии активаторов $[15,17,19]$. Значительное влияние на оптические свойства оказывает распределение активаторов в объеме и на поверхности частиц.

Для легирования $\mathrm{ZnS}$ и $\mathrm{CdS}$ широко применяются катионы $\mathrm{Mn}^{2+}[13,15,17,36,37]$. Их применение объясняется благоприятным структурным соответствием сульфидов цинка, кадмия и марганца, образованием рядов твердых растворов, а также различающейся растворимостью сульфидов матрицы $(\mathrm{ZnS}, \mathrm{CdS})$ и легирующего катиона $\mathrm{Mn}^{2+}(\mathrm{MnS})$ в реакционных средах при проведении химического синтеза с использованием золь-гель технологий.

Спектр люминесценции кристаллов $\mathrm{ZnS}: \mathrm{Mn}^{2+}$ содержит полосы рекомбинационного „самоактивированного“ излучения в голубой, $\sim(440-465)$ нм, и зеленой, $\sim 530$ нм, спектральных областях, а также полосу „марганцевого“ излучения в области 520-620 нм [13,38-41]. Кроме того, обнаруживаются красная и инфракрасная полосы в области длин волн 620-800 нм, которые связаны с состоянием поверхности частиц $[15,17,39,42]$.

„Марганцевое“ излучение возникает в результате перехода электронов между уровнями энергии ${ }^{4} T_{1} \rightarrow{ }^{6} A_{1}$ 
ионов $\mathrm{Mn}^{2+}$. Возникновение „марганцевой“ люминесценции связано с реализацией двух механизмов. Первый механизм основывается на резонансном сенсибилизационном переносе энергии полупроводниковой матрицы на возбужденные уровни ионов $\mathrm{Mn}^{2+}$. В работе [13] отмечается, что $d$-электронные состояния ионов $\mathrm{Mn}^{2+}$ действуют как эффективные люминесцентные центры. Они сильно взаимодействуют с $s$-p-электронными состояниями полупроводника матрицы $(\mathrm{ZnS})$, в которые обычно направляется внешнее электронное возбуждение. Данное электронное взаимодействие обеспечивает эффективный путь передачи энергии и приводит к высокой эффективности люминесценции легированных кристаллов ZnS:Mn при комнатной температуре [13]. Этот механизм реализуется при малой концентрации ионов марганца. Второй механизм начинает доминировать при увеличении концентрации ионов $\mathrm{Mn}^{2+}$. $\mathrm{Pe}-$ ализуется „электронный“ механизм, он связан с поглощением электронов при электровозбуждении или фотонов при оптическом возбуждении и переходами электронов между „собственными“ уровнями энергии ионов $\mathrm{Mn}^{2+}$ [15]. При селективном возбуждении в полосы поглощения ионов $\mathrm{Mn}^{2+}(390,435,470,496$ и 535 нм) в кристаллах $\mathrm{ZnS}: \mathrm{Mn}^{2+}$ наблюдается только полоса „марганцевой“ люминесценции [17]. Авторами работ $[17,36,37]$ показано, что независимо от концентрации ионов $\mathrm{Mn}^{2+}$ при незначительном изменении положения полосы (в пределах 10 нм) может существенно измениться ее интенсивность. Это связано с особенностями переноса энергии между уровнями в неэквивалентных активаторных центрах, имеющих различное локальное окружение ионов $\mathrm{Mn}^{2+}$, которое, кроме прочих факторов, зависит от условий синтеза легированных кристаллов.

В композициях $\mathrm{CdS}: \mathrm{Mn}^{2+}$ за счет резонансного механизма передачи энергии возбуждаются „марганцевые це центры, локализованные на поверхности нанокристаллов $\mathrm{CdS}[37,43,44]$. Композиции с наночастицами $(\mathrm{Cd}, \mathrm{Mn}) \mathrm{S}$, синтезированные совместным осаждением сульфидов, проявляют стабильную и яркую фотолюминесценцию в области 600 нм. При последовательном осаждении сульфидов кадмия и марганца с увеличением концентрации $\mathrm{MnS}$ на поверхности частиц образуется защитный слой сульфида марганца, который тушит люминесценцию [45].

Одним из способов получения наноразмерных полупроводниковых кристаллических структур является коллоидный синтез [36,43,46,47]. Его проводят в водной или органической средах. В водной среде синтез осложнен гидролизом. При его проведении требуется строгий контроль $\mathrm{pH}$ среды. В органических средах влияние воды минимизировано, однако возрастает вероятность агрегирования КТ. Размер КТ, как правило, не превышает 10 нм, размер агрегатов КТ достигает нескольких десятков нанометров [48-50]. Для стабилизации коллоидных растворов КТ применяются поверхностно-активные вещества. Например, в работе [13] таким веществом является метакриловая кислота. Увеличение эффективности фотолюминесценции нанокристаллического порошка $\mathrm{ZnS}: \mathrm{Mn}$ при возбуждении излучением с длиной волны 300 нм авторами [13] объясняется пассивацией поверхности частиц при фотополимеризации метакриловой кислоты. В ряде случаев стабилизирующим оказывается „зарядовый“ фактор [51]. Еще одним способом стабилизации является внедрение КТ и их структур в полимерные матрицы. Для получения полимерных композитов предварительно синтезированные КТ помещают в раствор полимера и отверждают [52-54] или синтезируют их непосредственно в процессе полимеризации мономера $[49,50]$. Во втором случае светопропускание акриловых композиций полимер/полупроводник при длинах волн > 450 нм достигает 90-92\% при толщине поглощающего слоя до 5 мм [48-50].

Число работ, посвященных изучению физико-химических характеристик и структуры многослойных квантовых точек „ядро/оболочка“ и ,ядро/оболочка/оболочка“, синтезированных и послойно легированных in situ в процессе формирования оптически прозрачной полимерной композиции, ограничено [45,48-50]. Проблемы изучения состава и структуры квантовых точек в подобных композициях соответствующими физическими методами связаны с тем, что частицы образуются одновременно с протеканием процесса полимеризации, они разрушаются при попытке выделить их из состава композиций растворением полимерной матрицы, предельная концентрация частиц, обеспечивающая высокую оптическую прозрачность композиций, ограничена. Примененный нами подход основывается на изучении люминесцентных свойств композиций, полученных при различных условиях формирования реакционных смесей и синтеза, и сравнении спектров с литературными данными для подобных объектов и объемного вещества.

Цель данной работы состояла в изучении фотолюминесцентных свойств и структуры наноразмерных частиц на основе сульфидов цинка, кадмия и марганца в полиакрилатной матрице, синтезированных in situ при различной последовательности введения предшественников - полупроводниковых $(\mathrm{CdS}, \mathrm{ZnS})$ и легирующего $\left(\mathrm{Mn}^{2+}\right)$ компонентов - в полимеризующуюся реакционную смесь и температурных условий синтеза.

\section{2. Характеристика объектов исследования и методики эксперимента}

Квантовые точки ( $\mathrm{Zn}, \mathrm{Cd}, \mathrm{Mn}) \mathrm{S}$ синтезированы по методике [55] разложением тиоацетамидных комплексов трифторацетатов цинка, кадмия и марганца в среде метилметакрилата (MМА) при нагревании и далее при его полимеризации. Концентрации трифторацетатов кадмия и цинка в конечных растворах (с учетом разведения при смешивании исходных растворов, если оно предусмотрено методикой) составляли по $5.0 \cdot 10^{-3}$ моль/л, 
концентрация трифторацетата марганца $5.0 \cdot 10^{-3}$ или $5.0 \cdot 10^{-4}$ моль/л. Конечный объем растворов во всех случаях составлял 10 мл.

При приготовлении растворов изменяли порядок введения реагентов, количество тиоацетамида (ТАА) и условия нагревания. При приготовлении первого раствора (1) в три пробирки раздельно поместили навески трифторацетатов кадмия, цинка и марганца, содержащие равные количества веществ. В каждую пробирку внесли эквивалентное соли металла количество тиоацетамида $(1: 1)$. Навески веществ растворили в метилметакрилате. Пробирку, содержащую раствор трифторацетата кадмия и TAA, нагрели на водяной бане при температуре $70-90^{\circ} \mathrm{C}$ в течение 10 мин. Ввели раствор, содержащий трифторацетат цинка и ТАА. Смесь перемешали и продолжили нагревание при тех же условиях в течение 10 мин. После нагревания ввели раствор трифторацетата марганца и ТАА. Раствор перемешали и продолжили нагревание при тех же условиях в течение 10 мин. Методика приготовления второго раствоpa (2) аналогична приготовлению раствора (1), однако концентрацию трифторацетата марганца в нем уменьшили в 10 раз. При приготовлении третьего раствора (3) в исходном растворе трифторацетата кадмия и ТАA двукратно увеличили содержание ТАA; раствор нагрели при тех же условиях, далее в него ввели раствор, содержащий эквивалентные трифторацетату кадмия количества трифторацетатов цинка и марганца, перемешали и продолжили нагревание, не изменяя условий. Четвертый раствор (4) приготовили аналогично раствору (1) в последовательности: раствор трифторацетата цинка и ТАA $(1: 1)$, раствор трифторацетата кадмия и ТАA $(1: 1)$, раствор трифторацетата марганца и ТАA $(1: 1)$. Приготовление пятого раствора (5) аналогично раствору (4), с десятикратно уменьшенным содержанием трифторацетата марганца. Приготовление шестого раствора (6) аналогично приготовлению раствора (3), однако начальным был раствор трифторацетата цинка. При приготовлении седьмого раствора (7) в трех пробирках приготовили исходные растворы трифторацетатов кадмия, цинка и марганца с эквивалентным количеством ТАА в каждой; пробирки нагрели при тех же условиях, после нагревания растворы объединили, перемешали и продолжили нагревание в течение 10 мин. При приготовлении раствора (8) в одну пробирку ввели равные количества трифторацетатов кадмия, цинка и марганца, трехкратное количество ТАA; смесь веществ растворили в ММА и нагрели при тех же условиях. Об образовании сульфидов металлов судили по изменению окраски растворов, первоначально бесцветные прозрачные растворы после нагревания приобрели желто-зеленую окраску сульфида кадмия различной интенсивности и оттенка. Коллоидная природа образовавшихся при нагревании растворов подтверждалась их опалесценцией.

Полимеризация коллоидных растворов была проведена аналогично [55] в присутствии перекиси бензоила при температуре $60-70^{\circ} \mathrm{C}$ в течение 24 ч.
В результате синтезированы полимерные „стекла“ ПMMA/(Zn, $\mathrm{Cd}, \mathrm{Mn}) \mathrm{S}$ с различной структурной организацией частиц $(\mathrm{Zn}, \mathrm{Cd}, \mathrm{Mn}) \mathrm{S}$. Светопропускание композиций в области длин волн > 450 нм достигает $92 \%$ (5 мм). Окраска „стекол“ близка к окраске полимеризуемых растворов. Изменение тона окраски от светлозеленого до светло-коричневого связано с различным распределением ионов $\mathrm{Cd}^{2+}$ и $\mathrm{Mn}^{2+}$ в кристаллических структурах сульфидов кадмия и цинка.

Электронные снимки продуктов сделаны методом просвечивающей электронной микроскопии (ПЭМ) на электронном микроскопе CM12 (Philips, Нидерланды). В этом случае для приготовления реакционных смесей вместо ММА применили этилацетат (ЭА, х.ч.). Эта замена позволила исключить влияние полимеризации MМА в процессе синтеза КТ. Коллоиды из растворов наносили на медные сетки с аморфным углеродным покрытием методом полива, высушивали и исследовали с различным увеличением. Для регистрации снимков полимерных композиций образец композиции растворяли в дихлорэтане (х.ч.), поливом наносили раствор на подложку микроскопа, высушивали и регистрировали электронный снимок образовавшейся пленки. Спектры фотолюминесценции и возбуждения фотолюминесценции композиций ПММA/(Zn, Cd, Mn)S зарегистрировали на спектрофлуориметре Shimadzu RF-5301PC по методике [49].

\section{3. Результаты эксперимента и их обсуждение}

Электронные снимки продуктов, выделенных из растворов и из полимерных композиций, приведены на рис. 1 ( $a, d-$ продукты предварительно выделены из коллоидных растворов, высушены при комнатной температуре, растворены в бутаноле-1 и поливом нанесены на медную сетку электронного микроскопа; $b, c$ непосредственно из раствора в ЭА поливом нанесены на медную сетку электронного микроскопа). На снимках видны агрегированные частицы, размером до 10 нм, размер агрегатов достигает десятков нанометров. Частицы и их агрегаты покрыты слоем комплексных соединений. На снимках аналогичных полимерных пленок наблюдаются равномерно распределенные скопления частиц (рис. $1, e, f)$ [50]. Результаты соответствуют данным, приведенным в работах [48-50].

$\mathrm{B}$ спектре люминесценции композиций ПММА/CdS зарегистрирована широкая полоса с максимумом в диапазоне длин волн 600-800 нм: см., например, рис. 2, спектр 1 [50]. Она связана с природой и концентрацией дефектов структуры на поверхности частиц CdS. Положение полосы зависит от концентрации легирующих ионов и их комплексов с компонентами матрицы $[49,50]$. При увеличении времени нагревания в процессе синтеза и „отжига“ композиций спектральная полоса и 

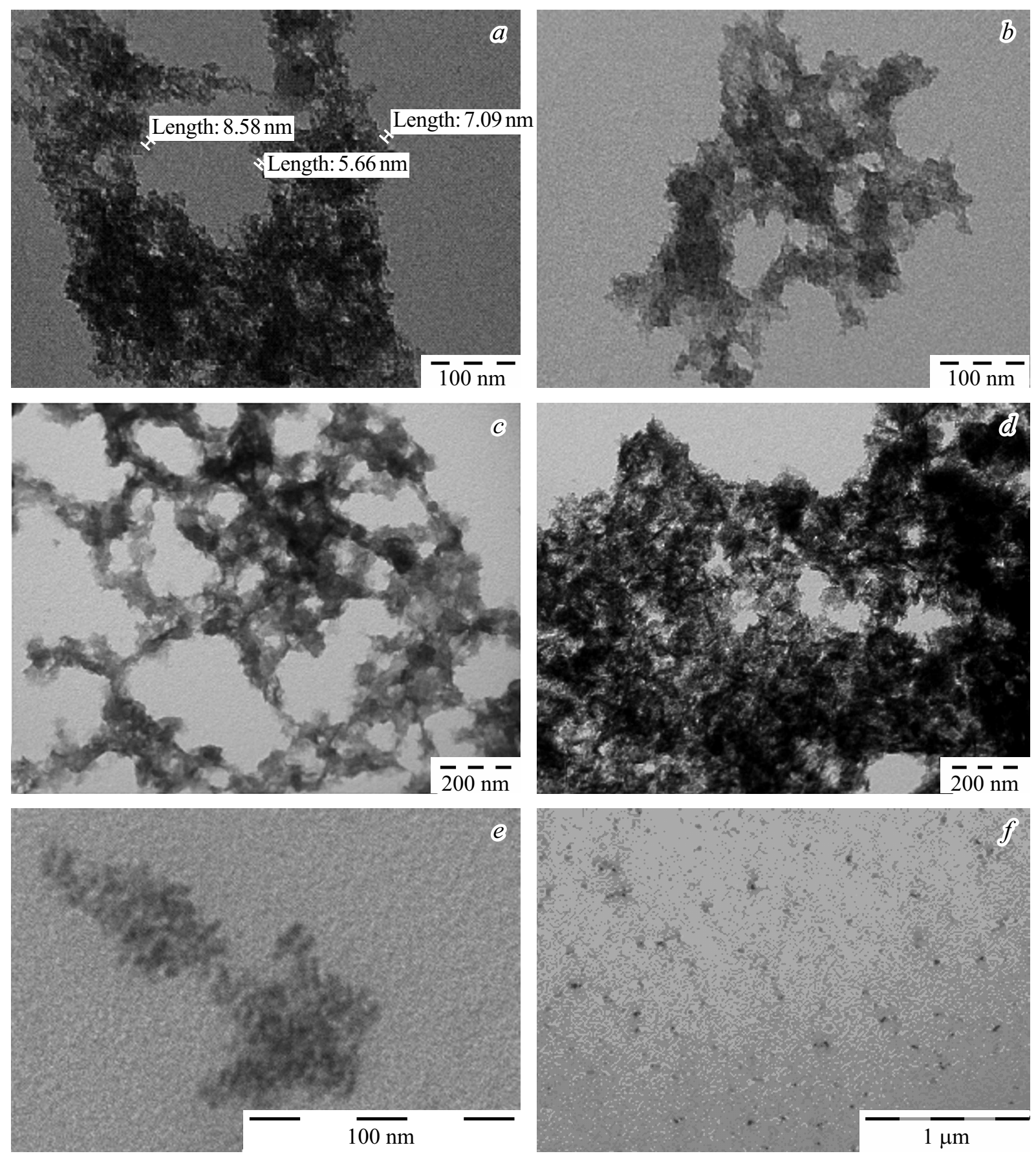

Рис. 1. Электронные снимки (ПЭМ) продуктов, выделенных до полимеризации из реакционных систем $\mathrm{Cd}\left(\mathrm{CF} \mathrm{C}_{3} \mathrm{COO}\right)_{2}-$ $\mathrm{Zn}\left(\mathrm{CF}_{3} \mathrm{COO}\right)_{2}-\mathrm{TAA}(a), \quad \mathrm{Cd}\left(\mathrm{CF}_{3} \mathrm{COO}\right)_{2}-\mathrm{Zn}\left(\mathrm{CF}_{3} \mathrm{COO}\right)_{2}-\mathrm{Mn}\left(\mathrm{CF}_{3} \mathrm{COO}\right)_{2}-\mathrm{TAA}-$ ЭA $(b), \quad \mathrm{Cd}\left(\mathrm{CF}{ }_{3} \mathrm{COO}\right)_{2}-\mathrm{Mn}\left(\mathrm{CF}_{3} \mathrm{COO}\right)_{2}-$ $\mathrm{TAA}-Э \mathrm{~A})(c), \mathrm{Cd}\left(\mathrm{CF}_{3} \mathrm{COO}\right)_{2}-\mathrm{Mn}\left(\mathrm{CF}_{3} \mathrm{COO}\right)_{2}-\mathrm{TAA}(d) ; \Pi \mathrm{MMA} /(\mathrm{Cd}, \mathrm{Pb}) \mathrm{S}[50](e, f)$.

ее максимум претерпевают гипсохромный сдвиг в область 600 нм. Он объясняется разрушением комплексов и формированием более однородной поверхности частиц. Внедрение легирующих катионов в поверхность частиц и увеличение концентрации комплексов приводит к „красному“ смещению полосы $[49,50,56]$. Коротковолновая полоса люминесценции $\mathrm{CdS}$ в композициях ПMМA/CdS, связанная с дефектами структуры в объеме кристаллов, проявляется с малой интенсивностью или вообще отсутствует [48-50,56].

Возбуждение люминесценции композиций ПMМA/CdS происходит при воздействии на образец электромагнитным излучением с длинами волн в диапазоне 280-480 нм. В спектре возбуждения зарегистрирована широкая сложная полоса, которая перекрывается с областью фундаментального поглощения $\mathrm{CdS}[50,56]$. 


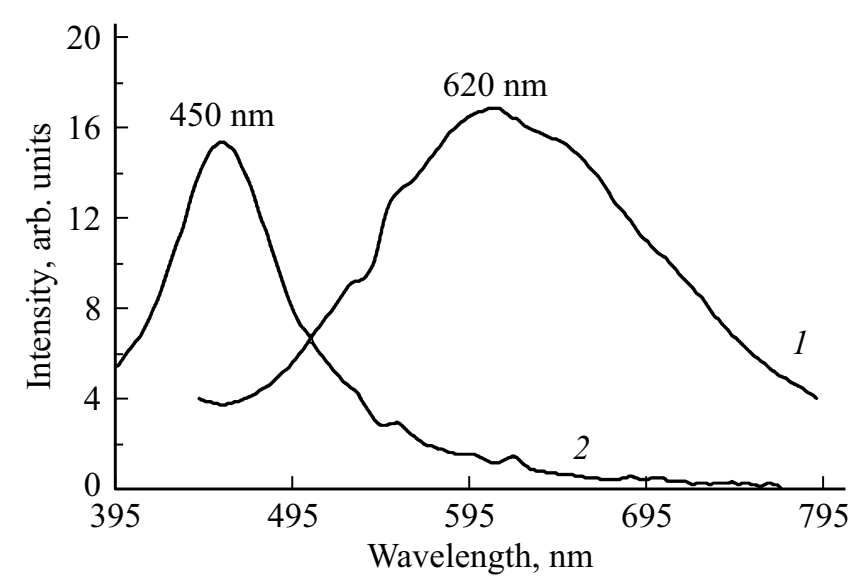

Рис. 2. Спектры люминесценции при возбуждении с длиной волны $\lambda_{\mathrm{ex}}=370$ нм композиций ПMМA/CdS (1) и ПММA/ZnS (2). Концентрации компонентов: $C_{\mathrm{Cd}}=C_{\mathrm{Zn}}$ $=C_{\mathrm{TAA}}=1.0 \cdot 10^{-2}$ моль/л $[50]$.

Это указывает на реализацию механизма, в результате которого электроны из зоны проводимости переходят на уровни дефектов структуры $\mathrm{CdS}$ с последующей рекомбинацией, сопровождающейся выделением квантов энергии [19].

В спектре люминесценции композиций ПММА/ZnS зарегистрирована сложная полоса в интервале длин волн 350-600 нм. Она содержит до 4 компонент [14,57,58]. С увеличением длины волны возбуждающего излучения интенсивности компонент перераспределяются. Это приводит к батохромному смещению общего максимума. Изменения в спектре связаны с неоднородностью люминесцирующих центров в объеме и на поверхности частиц, требующих различной энергии возбуждения.

Возбуждение люминесценции композиций ПMMA/ZnS происходит в результате межзонного перехода электронов, а также переходов из валентной зоны непосредственно на уровни дефектов структуры $\mathrm{ZnS}$. При возбуждении излучением с длиной волны 370 нм максимум полосы люминесценции соответствует длине волны $\sim 450$ нм (рис. 2, спектр 2) [50].

Результаты исследования акрилатных композиций, модифицированных КТ сульфида цинка, активированного ионами $\mathrm{Mn}^{2+}$, приведены в работе [59]. В спектрах люминесценции композиций зарегистрировано две широкие полосы с максимумами в областях длин волн 400-460 и > 550 нм. Длинноволновая полоса отнесена к люминесценции ионов $\mathrm{Mn}^{2+}$, возникающей в результате перехода электронов между уровнями энергии ${ }^{4} T_{1} \rightarrow{ }^{6} A_{1}$ марганца. Она наблюдается при возбуждении излучением с длиной волны 330 нм. Положение полосы совпадает с данными, приведенными в работе [13]. При бо́льших длинах волн возбуждающего излучения (365 и 390 нм) она исчезает и с небольшой интенсивностью появляется в спектре только при увеличении концентрации ионов $\mathrm{Mn}^{2+}$, при этом необходимо учитывать влияние ионов
$\mathrm{Pb}^{2+}$, которые также находятся в системе в качестве соактиваторов сульфида цинка [59].

В спектрах возбуждения люминесценции зарегистрирован набор сложных полос при длинах волн 280-420 нм, а также полоса небольшой интенсивности с максимумом в области 256 нм [59]. Коротковолновые компоненты полосы в области длин волн $<330 \mathrm{Hм}$ перекрываются с областью фундаментального поглощения ZnS. Это позволяет сделать заключение о том, что возбуждение люминесценции ${ }^{4} T_{1} \rightarrow{ }^{6} A_{1}$ ионов $\mathrm{Mn}^{2+}$ связано с переносом энергии непосредственно из зоны проводимости $\mathrm{ZnS}$ на уровни ионов $\mathrm{Mn}^{2+}$ и далее происходит дезактивация с выделением части энергии в виде люминесцентного излучения. Положение и ширина полосы соответствуют данным [13], как и наличие в спектре возбуждения полосы с максимумом в области $<300$ нм (256 нм). Значительное коротковолновое смещение полосы возбуждения в спектре наночастиц $\mathrm{ZnS}: \mathrm{Mn}$, отмеченное авторами [13] со ссылкой на [60], связано с увеличением $s-p$-электронной запрещенной зоны в нанокристаллах $\mathrm{ZnS}$ малого размера, стабилизирующихся в результате фотополимеризации на их поверхности метакриловой кислоты. Исчезновение в спектрах полосы люминесценции ионов $\mathrm{Mn}^{2+}$ при возбуждении длинноволновым излучением указывает на ограничение переноса энергии на возбужденные уровни ионов $\mathrm{Mn}^{2+}$ с уровней дефектов структуры $\mathrm{ZnS}$ [59].

Неоднородное уширение полос в спектрах люминесценции и возбуждения люминесценции композиций объясняется полиморфизмом сульфидов, политипностью структуры кристаллов при их формировании в ядрах коллоидных частиц, дисперсностью частиц, влиянием кислорода $[14,16,61,62]$; также сказываются комплексообразование на поверхности частиц, аморфность и собственная люминесценция матрицы $[49,50,63]$.

Люминесценцию композиций ПММА/ $(\mathrm{Zn}, \mathrm{Cd}) \mathrm{S}$, синтезированных в условиях, обеспечивающих образование частиц с различным сочетанием слоев сульфидов кадмия и цинка $(\mathrm{ZnS} / \mathrm{CdS}$ или $\mathrm{CdS} / \mathrm{ZnS})$, определяет сульфид кадмия [55]. Это объясняется меньшей шириной запрещенной зоны $\mathrm{CdS}$. В спектрах всех синтезированных композиций зарегистрирована длинноволновая полоса люминесценции $\mathrm{CdS}$. Ее положение и интенсивность изменяются в зависимости от последовательности введения предшественников сульфидов кадмия и цинка в реакционную смесь, определяющей структуру образующихся частиц, и от температурных условий синтеза [55]. В спектрах композиций ПММА/[(Cd, Zn) $\mathrm{S} /(\mathrm{Zn}, \mathrm{Cd}) \mathrm{S}]$, содержащих частицы с ядром $\mathrm{CdS}$, легированным ионами $\mathrm{Zn}^{2+}$, покрытым оболочкой $\mathrm{ZnS}$, легированной ионами $\mathrm{Cd}^{2+}$, кроме длинноволновой полосы люминесценции, связанной с $\mathrm{CdS}$, наблюдалась коротковолновая полоса, связанная с люминесценцией сульфида цинка [55]. Возбуждение люминесценции происходит в результате межзонного перехода электронов в полупроводниках и их переходов из валентной зоны на уровни дефектов структуры кристаллов [55]. 


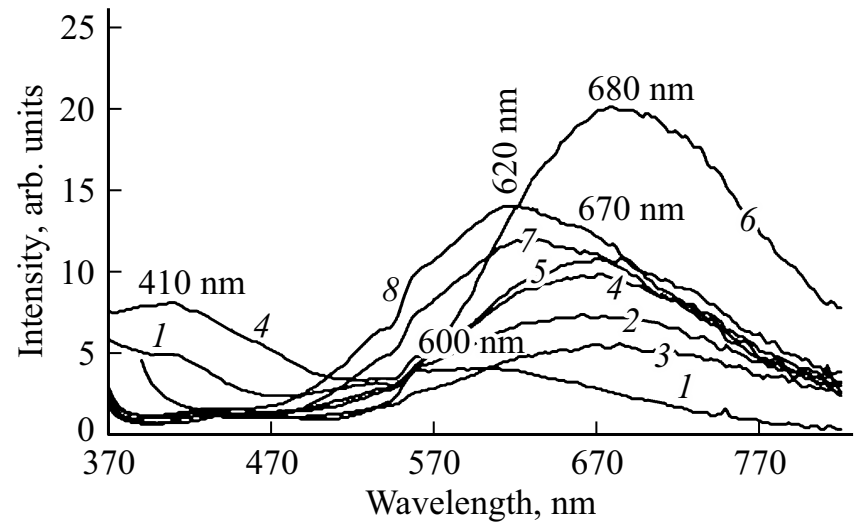

Рис. 3. Спектры люминесценции при длине волны возбуждения $\lambda_{\mathrm{ex}}=330$ нм композиций ПММА/ $\left.\mathrm{Zn}, \mathrm{Cd}, \mathrm{Mn}\right) \mathrm{S}$ (номера кривых соответствуют номерам образцов 1-8). Концентрации веществ в полимеризуемых реакционных смесях, моль/л: $1,4,7,8-C_{\mathrm{Zn}}=C_{\mathrm{Cd}}=C_{\mathrm{Mn}}=5.0 \cdot 10^{-3}, C_{\mathrm{TAA}}=1.5 \cdot 10^{-2}$; $2,5-C_{\mathrm{Zn}}=C_{\mathrm{Cd}}=5.0 \cdot 10^{-3}, \quad C_{\mathrm{Mn}}=5.0 \cdot 10^{-4}, \quad C_{\mathrm{TAA}}=$ $=1.0 \cdot 10^{-2} ; 3,6-C_{\mathrm{Zn}}=C_{\mathrm{Cd}}=C_{\mathrm{Mn}}=5.0 \cdot 10^{-3}, C_{\mathrm{TAA}}=$ $=1.0 \cdot 10^{-2}$.

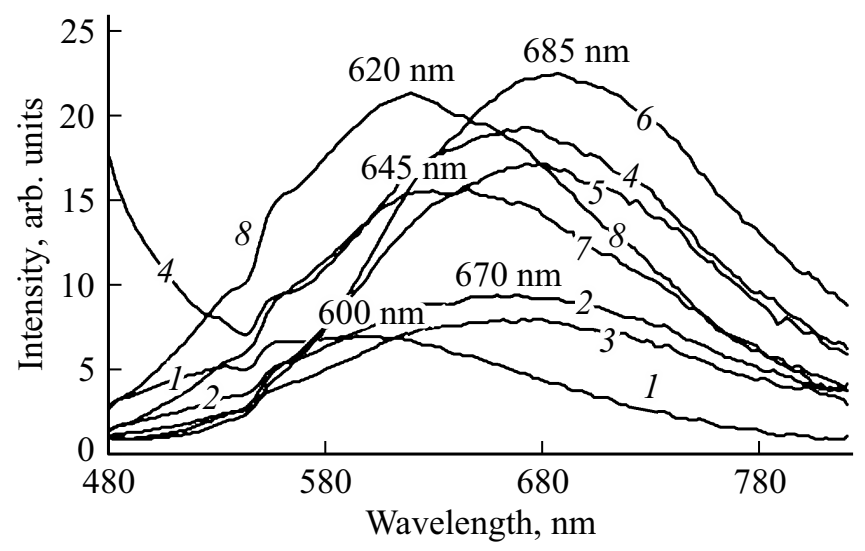

Рис. 4. Спектры люминесценции при длине волны возбуждения $\lambda_{\mathrm{ex}}=390$ нм композиций ПММА/ $\left.\mathrm{Zn}, \mathrm{Cd}, \mathrm{Mn}\right) \mathrm{S}$ (номера кривых соответствуют номерам образцов 1-8). Концентрации веществ в полимеризуемых реакционных смесях, моль/л: $1,4,7,8-C_{\mathrm{Zn}}=C_{\mathrm{Cd}}=C_{\mathrm{Mn}}=5.0 \cdot 10^{-3}, C_{\mathrm{TAA}}=1.5 \cdot 10^{-2}$; $2,5-C_{\mathrm{Zn}}=C_{\mathrm{Cd}}=5.0 \cdot 10^{-3}, \quad C_{\mathrm{Mn}}=5.0 \cdot 10^{-4}, \quad C_{\mathrm{TAA}}=$ $=1.0 \cdot 10^{-2} ; 3,6-C_{\mathrm{Zn}}=C_{\mathrm{Cd}}=C_{\mathrm{Mn}}=5.0 \cdot 10^{-3}, C_{\mathrm{TAA}}=$ $=1.0 \cdot 10^{-2}$.

Спектры фотолюминесценции композиций ПММA/(Zn, Cd, Mn)S (1-8), зарегистрированные при возбуждении излучением с длинами волн 330 и 390 нм, приведены на рис. 3 и 4. Они различаются интенсивностью и положением полос. Это связано с преобладанием люминесценции различных центров, требующих разной энергии возбуждения, а также с условиями переноса энергии между уровнями. Из всех композиций, полученных с использованием разных методик синтеза и соответственно имеющих разную структуру образовавшихся КТ, в двух случаях в спектрах зарегистрирована полоса с максимумом в области 410 нм (рис. 3, спектры 1 и 4). В спектрах всех композиций присутствует широкая полоса с максимумом, расположенным в интервале длин волн 600-700 нм.

Положение максимума коротковолновой полосы люминесценции (рис. 3, спектры 1 и 4), с учетом отмеченного авторами $[15,17]$ гипсохромного смещения в полупроводниковых кристаллах, легированных ионами $\mathrm{Mn}^{2+}$, подтверждает формирование в композициях 1 и 4 дефектов, образованных ионами $\mathrm{Mn}^{2+}$ в объеме слоев структуры. Их люминесценция связана с рекомбинацией зарядов на соответствующих этим дефектам уровнях энергии [19].

Длинноволновая полоса люминесценции в спектре композиции 1 характеризуется наибольшим коротковолновым смещением максимума $(600$ нм) и наименьшей интенсивностью (рис. 3 и 4, спектры 1). Образцы 1 отличаются более насыщенной окраской. Это соотносится с результатами, приведенными в работе [45], для композиции ПММА/ $(\mathrm{Cd}, \mathrm{Mn}) \mathrm{S}$, синтезированной при последовательном осаждении сульфидов кадмия и марганца. Отличие от результатов, полученных для композиций ПММА/(Zn, Cd)S, синтезированных по аналогичной методике [55], заключается в существенном гипсохромном смещении максимума полосы. Это подтверждает участие уровней, образованных ионами $\mathrm{Mn}^{2+}$, в эмиссионных процессах и соответствует предположениям [13] об усилении взаимодействия $d$-электронов ионов $\mathrm{Mn}^{2+}$ с $s-p$-электронной системой полупроводниковой структуры, приводящем к увеличению энергии межзонного перехода в наночастицах малого размера. Сопоставление спектров, приведенных на рис. 3, 4 и в работах $[13,45,55]$, позволяет предположить, что в результате реализации методики 1 сформированы КТ состава $\mathrm{CdS} /(\mathrm{Zn}, \mathrm{Mn}) \mathrm{S}: \mathrm{Mn}^{2+}$ с достаточно большой концентрацией ионов $\mathrm{Mn}^{2+}(\mathrm{MnS})$ в приповерхностном слое и на поверхности частиц, блокирующих люминесценцию. Данные композиции соответствуют формуле ПММА/CdS/(Zn, Mn)S: $\mathrm{Mn}^{2+}$. Предполагаемая формула, как и во всех последующих случаях, содержит символы преобладающих компонентов. Первым в формуле указывается катион полупроводниковой матрицы, следующие - легирующие катионы, например: $(\mathrm{Zn}, \mathrm{Mn}) \mathrm{S}: \mathrm{Mn}^{2+}$ - полупроводниковая матрица образована сульфидом цинка, катионы марганца входят в ее объем в качестве легирующего компонента; $\mathrm{Mn}^{2+}-$ ионы на поверхности частиц. В большинстве формул не указываются ионы $\mathrm{Zn}^{2+}$ и $\mathrm{Cd}^{2+}$, которые находятся на поверхности частиц, и ионы, которые находятся в полимерной матрице в не связанном с полупроводниковыми частицами виде.

Композиция 2 (рис. 3 и 4, спектры 2) синтезирована аналогично композиции 1. Отличие заключается в меньшей концентрации трифторацетата марганца. В исходной реакционной смеси для получения композиции 2 она на порядок меньше, чем в смеси для получения композиции 1. Отсутствие в спектре люминесценции корот- 
коволновой полосы и значительное батохромное смещение длинноволновой полосы $(600 \rightarrow 670$ нм $)$ объясняется преимущественным расположением ионов $\mathrm{Mn}^{2+}$ на поверхности частиц. Данное предположение исходит из более высокой растворимости $\mathrm{MnS}$ по сравнению с растворимостью $\mathrm{ZnS}$ и $\mathrm{CdS}$, ограничивающей внедрение ионов $\mathrm{Mn}^{2+}$ в объем кристаллических структур сульфидов цинка и кадмия. Композициям приписана формула ПММА/(CdS/ZnS $): \mathrm{Mn}^{2+}$.

Композиция 3 синтезирована введением раствора трифторацетатов цинка и марганца в раствор трифторацетата кадмия, содержащий двукратный избыток ТАА, после его нагревания и дальнейшим нагреванием полученной смеси для продолжения реакции. Данная методика синтеза аналогична методике синтеза 5 композиций ПММА/ $(\mathrm{Cd}, \mathrm{Zn}) \mathrm{S}$, приведенной в работе [55]. Влияние ионов $\mathrm{Mn}^{2+}$ проявляется в батохромном смещении максимума полосы люминесценции (626 [55] $\rightarrow 678$ нм) и уменьшении ее интенсивности. Эти отличия объясняются формированием на поверхности частиц оболочки комплексов цинка и марганца с преимущественной люминесценцией, связанной с дефектами в приповерхностном слое и на поверхности частиц. Увеличение концентрации комплексов на поверхности частиц объясняется отсутствием ТАА в растворе трифторацетатов цинка и марганца, который необходим для образования сульфидов. Отсутствие коротковолновой люминесценции связано с недостаточной концентрацией $\mathrm{ZnS}$, а также перекрыванием его люминесценции с полосами поглощения ионов $\mathrm{Mn}^{2+}[15,17]$. Композиции можно описать формулами ПММА/[CdS/(Zn, Mn)S $]: \mathrm{Mn}^{2+}, \mathrm{Zn}^{2+}$ и ПММА/(Cd, $\mathrm{Zn}, \mathrm{Mn}) \mathrm{S}: \mathrm{Mn}^{2+}, \mathrm{Zn}^{2+}$.

Синтез композиции 4 отличался от синтеза композиции 1 последовательностью введения компонентов в реакционную смесь. Исходная смесь состояла из трифторацетата цинка и ТАА. В нее после нагревания последовательно вводили растворы трифторацетатов кадмия и марганца, содержащие эквивалентные количества ТАА. В спектрах люминесценции (рис. 3 и 4, спектры 4) зарегистрированы достаточно интенсивные полосы с максимумами в области 672 нм. Отмечаем увеличение интенсивности полосы при возбуждении излучением с длиной волны 390 нм (рис. 4, спектр 4), как, впрочем, и в ряде других случаев синтеза. Это, если исходить из условий синтеза, соответствует протеканию процессов переноса энергии возбуждения из зоны $\mathrm{CdS}$. Отличие от спектра композиции 1 ПММА/( Cd, Zn)S [55] заключается в гипсохромном смещении максимума полос $(684[55] \rightarrow 672$ нм $)$ и появлении коротковолновой полосы с максимумом при $\sim 410$ нм. Аналогичное гипсохромное смещение полосы наблюдалось для композиции ПММА/(Cd, Mn)S [55] относительно полосы в спектре композиции ПММА/CdS [45]. Эти отличия объясняются участием „марганцевых“ центров в составе внешней оболочки кристаллов в процессах поглощения и люминесценции. Внедрение ионов $\mathrm{Zn}^{2+}$ во внешнюю оболочку $\mathrm{CdS}$ предполагаем из-за большей рас- творимости $\mathrm{ZnS}$ по сравнению с растворимостью $\mathrm{CdS}$. Вероятный состав композиции представлен формулой ПММА/[ZnS/(Cd, Zn, Mn $) \mathrm{S}]: \mathrm{Mn}^{2+}$.

Синтез композиций 5 проведен аналогично синтезу композиции 4. Отличие заключается в десятикратном уменьшении концентрации трифторацетата марганца в реакционной смеси и соответственно уменьшении их концентрации в объеме частиц. Как и в предыдущем случае (композиция 4), интенсивность полос люминесценции больше при возбуждении излучением с длиной волны 390 нм. Сравнивая спектры люминесценции композиций 4 и 5 (рис. 3 и 4), отметим бо́льшую интенсивность полосы люминесценции композиции 5 при возбуждении излучением с длиной волны $330 \mathrm{Hм}$ (рис. 3). В спектрах люминесценции на рис. 4 соотношение интенсивностей обратное. Во втором случае (рис. 4) максимум полосы композиции 5 смещен в область длинных волн $(672 \rightarrow 680$ нм $)$ относительно максимума композиции 4. Расположение полосы и ее максимума так же, как и в предыдущем случае (композиция 4), указывают на преобладание „марганцевых“ центров люминесценции на поверхности частиц $[15,17]$. Увеличение интенсивности люминесценции композиции 5 при возбуждении излучением с длиной волны 330 нм (рис. 3, спектр 5) может происходить в результате усиления взаимодействия между ионами $\mathrm{Zn}^{2+}-\mathrm{Mn}^{2+}$, сопровождающегося переносом энергии $\mathrm{ZnS}$ на уровни дефектов, образованных с участием ионов $\mathrm{Mn}^{2+}$. Предполагаем следующий состав композиции: ПММА/[ZnS/(Cd, $\mathrm{Zn}) \mathrm{S}]: \mathrm{Mn}^{2+}$.

В спектре композиции 6 наблюдается полоса наибольшей интенсивности с максимальным батохромным смещением. Ее максимум расположен в области длин волн 680-685 нм и зависит от длины волны возбуждающего излучения (рис. 3 и 4, спектр 6). Методика синтеза данной композиции аналогична методике синтеза композиции 4 (ПММА/Cd, Zn)S [55]. $\mathrm{B}$ спектрах обеих композиций полоса является наиболее интенсивной. Длинноволновое смещение полосы $(642[55] \rightarrow 686$ нм) связываем с комплексообразованием на поверхности частиц. Это объясняется введением в предварительно нагретую исходную реакционную смесь $\mathrm{Zn}\left(\mathrm{CF}_{3} \mathrm{COO}\right)_{2}+2 \mathrm{TAA}$ растворов трифторацетатов кадмия и марганца без ТАA с последующим нагреванием полученного раствора, а также избытком суммарного мольного содержания ионов металлов в реакционной смеси относительно мольного содержания ТАА (3/2). Предполагаемый состав композиций соответствует формуле ПММА/[ZnS/(Cd, Zn, Mn)S]: $\mathrm{Mn}^{2+}, \mathrm{Cd}^{2+}$.

В спектре композиции 7 зарегистрирована длинноволновая полоса средней интенсивности с максимумом при 646 нм (рис. 3 и 4, спектр 7). Относительно полосы в спектре композиции 3 (ПММА/Cd, Zn)S [55] она смещена в область длинных волн (598 [55] $\rightarrow 645$ нм). Учитывая то, что синтез для каждого из сульфидов был начат в отдельном реакционном сосуде, вероятно образование 


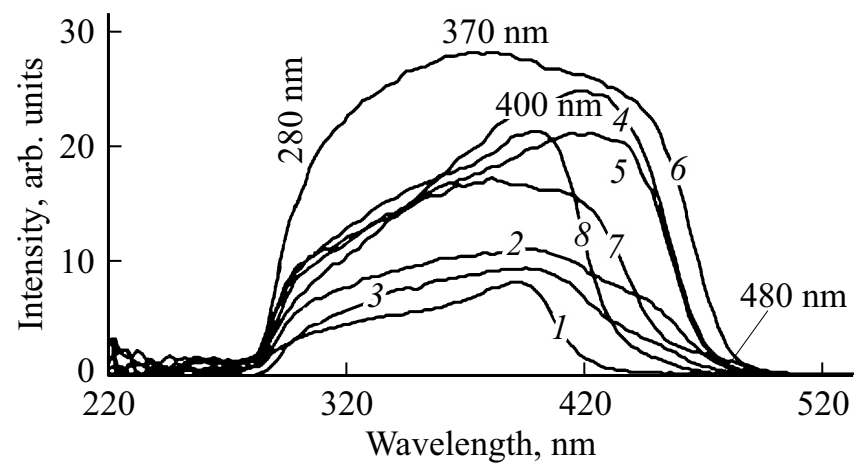

Pис. 5. Спектры возбуждения люминесценции на длине волны регистрации $\lambda_{\mathrm{L}}=680$ нм композиций (номера кривых соответствуют номерам образцов $1-8)$. Концентрации веществ в полимеризуемых реакционных смесях, моль/л: 1, 4, 7, 8 $C_{\mathrm{Zn}}=C_{\mathrm{Cd}}=C_{\mathrm{Mn}}=5.0 \cdot 10^{-3}, \quad C_{\mathrm{TAA}}=1.5 \cdot 10^{-2} ; \quad 2,5-$ $C_{\mathrm{Zn}}=C_{\mathrm{Cd}}=5.0 \cdot 10^{-3}, \quad C_{\mathrm{Mn}}=5.0 \cdot 10^{-4}, \quad C_{\mathrm{TAA}}=1.0 \cdot 10^{-2}$; $3,6-C_{\mathrm{Zn}}=C_{\mathrm{Cd}}=C_{\mathrm{Mn}}=5.0 \cdot 10^{-3}, C_{\mathrm{TAA}}=1.0 \cdot 10^{-2}$.

частиц разного состава. Это также явилось причиной отсутствия коротковолновой полосы люминесценции в области $<500$ нм. Люминесценция связана с „марганцевыми“ центрами. Предполагаемый состав композиций отражают следующие формулы: ПММА/(Zn, Cd, Mn)S: $\mathrm{Mn}^{2+}$ и ПММА $/(\mathrm{Cd}, \mathrm{Zn}, \mathrm{Mn}) \mathrm{S}: \mathrm{Mn}^{2+}$.

В спектре композиции 8 также зарегистрирована одна из самых интенсивных полос люминесценции с максимумом при 620 нм (рис. 3 и 4, спектр 8). Синтез данной композиции аналогичен синтезу композиции 6 ПММА/(Cd,Zn)S [55]. Отличие заключается в гипсохромном смещении максимума полосы люминесценции $(630[55] \rightarrow 620$ нм). Люминесценцию связываем со свечением „марганцевых“ центров в объеме кристаллов сульфидов. Предполагаем следующий состав композиции: ПММА/[(Cd, Zn, Mn)S/(Zn, Cd, Mn $) \mathrm{S}]: \mathrm{Mn}^{2+}$.

В спектрах возбуждения композиций 1-8 (рис. 5) зарегистрирована сложная широкая полоса в диапазоне длин волн 280-500 нм. В зависимости от состава и структуры композиций ниспадающая ветвь полосы смещается в длинноволновую область спектра. Батохромный сдвиг края полосы поглощения вызван особенностями структуры полупроводниковой матрицы, обеспечивающей перенос энергии возбуждения из зоны проводимости $\mathrm{ZnS}, \mathrm{CdS}$ или смешанной структуры $(\mathrm{Zn}, \mathrm{Cd}) \mathrm{S}$, внедрением легирующих ионов в кристаллическую структуру полупроводниковой матрицы, а также увеличением размера частиц при послойном нанесении сульфидов на ядро КТ и образованием комплексных соединений на поверхности частиц. Следует отметить, что при данном возбуждении наиболее полно аккумуляция энергии происходит в композиции 6 (рис. 5, спектр 6), наиболее эффективно, как следует из сопоставления площадей полос в спектрах люминесценции и возбуждения, поглощенная энергия преобразуется в люминесценцию композицией 8.

\section{4. Заключение}

Методом коллоидного синтеза в среде метилметакрилата синтезированы КТ на основе сульфидов кадмия и цинка и их структуры „ядро/оболочка“, легированные ионами $\mathrm{Mn}^{2+}$. Термической полимеризацией ММА в блоке коллоидные растворы переведены в стеклообразное состояние. Синтезированы композиции вида ПMМА/ $(\mathrm{Zn}, \mathrm{Cd}, \mathrm{Mn}) \mathrm{S}$, различающиеся составом ядра и оболочки, а также распределением между слоями легирующих компонентов. Показано, что различное сочетание исходных растворов, содержащих трифторацетаты кадмия, цинка, марганца и ТАА, условия нагревания смесей оказывают влияние на спектр люминесценции композиций. В спектрах наблюдаются одна или две широкие сложные полосы люминесценции. Коротковолновая полоса связана с люминесценцией ионов $\mathrm{Mn}^{2+}$, формирующих дефекты в кристаллической структуре, образованной сульфидами кадмия и цинка, преобразующие энергию межзонного полупроводникового перехода в видимое излучение. Сложная длинноволновая полоса люминесценции связана с реализацией рекомбинационных процессов на уровнях дефектов в кристаллической структуре поверхности частиц, а также с электронными переходами между собственными уровнями энергии ${ }^{4} T_{1} \rightarrow{ }^{6} A_{1}$ ионов $\mathrm{Mn}^{2+}$, возбуждающимися в результате сенсибилизационного переноса энергии, поглощенной полупроводниковой матрицей при межзонном переходе электронов. На основании анализа спектров композиций высказаны предположения о составе и структуре КТ, а также об эффективности преобразования поглощенной энергии в люминесцентное излучение.

\section{Финансирование работы}

Исследование выполнено при финансовой поддержке РФФИ в рамках научного проекта № 19-33-90023.

\section{Конфликт интересов}

Авторы заявляют, что у них нет конфликта интересов.

\section{Список литературы}

[1] D. Vasudevan, R.R. Gaddam, A. Trinchi, I.J. Cole. J. Alloys Compd., 636, 395 (2015).

[2] H.P. Feng, L. Tang, G.M. Zeng, X. Ren, B. Song, C. Liang, M.Y. Wei, J.F. Yu, Y. Zhou, Y.C. Deng. Adv. Colloid Interface, 267, 26 (2019).

[3] H. Zhao, F. Rosei. Chem., 3, 229 (2017).

[4] A.M. El-Toni, M.A. Habila, J.P. Labis, Z.A. Alothman, M. Alhoshan, A.A. Elzatahry, F. Zhang. Nanoscale, 8(5), 2510 (2016).

[5] T.A. Esquivel-Castro, M.C. Ibarra-Alonso, J. Oliva, A. Martínez-Luévanos. Mater. Sci. Eng. C, 96, 915 (2019).

[6] W. Lu, X. Guo, Y. Luo, Q. Li, R. Zhu, H. Pang. Chem. Eng. J., 355, 208 (2019). 
[7] P.K. Kalambate, Dhanjai, H. Zhimei, Y. Li, S. Yue, X. Meilan, H. Yunhui, S. Ashwini. Trends Anal. Chem., 115, 147 (2019).

[8] P. Mélinon, S. Begin-Colin, J.L. Duvail, F. Gauffre, N.H. Boime, G. Ledoux, J. Plain, P. Reiss, F. Silly, B. WarotFonrose. Phys. Rep., 543 (3), 163 (2014).

[9] R. Ghosh Chaudhuri, S. Paria. Chem. Rev., 112, 2373 (2011).

[10] M.B. Gawande, A. Goswami, R. Zboril, T. Asefa, H. Guo, D.-L. Peng, A.V. Biradar, R.S. Varma. Chem. Soc. Rev., 44 (21), 7540 (2015).

[11] H. Kumar, A. Kumari, R.R. Singh. Optical. Mater., 69, 23 (2017).

[12] О.Н. Казанкин, Л.Я. Марковский, И.А. Миронов, Ф.М. Пекерман, Л.Н. Петошина. Неорганические люминофоры (Л., Химия, 1975).

[13] R.N. Bhargava, D. Gallagher, X. Hong, A. Nurmikko. Phys. Rev. Lett., 72, 416 (1994).

[14] D. Denzler, M. Olschewski, K. Sattler. J. Appl. Phys., 84 (5), 2841 (1998).

[15] М.Ф. Буланый, Б.А. Полежаев, Т.А. Прокофьев. ФТП, 32 (6), 673 (1998).

[16] Н.К. Морозова, И.А. Каретников, Д.А. Мидерос, Е.М. Гаврищук, В.Б. Иконников. ФТП, 40 (10), 1185 (2006).

[17] М.Ф. Буланый, А.В. Коваленко, Б.А. Полежаев, Т.А. Прокофьев. ФТП, 43 (6), 745 (2009).

[18] T.V. Vineeshkumar, R.D. Rithesh, S. Prasanth, N.V. Unnikrishnan, R. Philip, C. Sudarsanakumar. Optical. Mater., 37, 439 (2014).

[19] J.K. Saluja, Y. Parganiha, N. Tiwari, V. Dubey, R. Tiwari, A. Prabhath. Optik, 127, 7958 (2016).

[20] К.А. Огурцов, М.М. Сычев, В.В. Бахметьев, В.Н. Коробко, А.И. Поняев, Ф.И. Высикайло, В.В. Беляев. Неорг. матер., 52 (11), 1188 (2016).

[21] T.V. Vineeshkumar, D. Rithesh Raj, S. Prasanth, Pranitha Sankar, N.V. Unnikrishnan, V.P. Mahadevan Pillai, C. Sudarsanakumar. Optical. Mater., 58, 128 (2016).

[22] Y. Lu, Y.Q. Zhang, X.A. Cao. Appl. Phys. Lett., 102 (2), 023106 (2013).

[23] D.V. Talapin, I. Mekis, S. Götzinger, A. Kornowski, O. Benson, H. Weller. J. Phys. Chem. B, 108 (49), 18826 (2004).

[24] C. Rosiles-Perez, Cerdán-Pasarán, S. Sidhik, D. Esparza, T. Lopez-Luke, E. de la Rosa. Solar Energy, 174, 240 (2018).

[25] N.S.M. Mustakim, C.A. Ubani, S. Sepeai, N.A. Ludin, M.A.M. Teridi, M.A. Ibrahim. Solar Energy, 163, 256 (2018).

[26] N. Qutub, B.M. Pirzada, K. Umar, O. Mehraj, M. Muneer, S. Sabir. Physica E, 74, 74 (2015).

[27] W. Cao, X. Zhang, Y. Zheng, K. Wang, H. Dai. Int. J. Hydrogen Energy, 42 (5), 2924 (2017).

[28] P. Kunstman, J. Coulon, O. Kolmykov, H. Moussa, L. Balan, Gh. Medjahdi, J. Lulek, R. Schneider. J. Luminesc., 194, 760 (2018).

[29] Ch.V. Reddy, J. Shim, M. Cho. J. Phys. Chem. Solids, 103, 209 (2017).

[30] M. Abdel Rafea, A.A.M. Farag, O. El-Shazly, E.F. El-Wahidy, N. Roushdy. Microelectron. Eng., 122, 40 (2014).

[31] M. Ashraf, S.S. Hussain, S. Riaz, S. Naseem. Materials Today: Proceedings, 2 (10-B), 5695 (2015).

[32] S.R. Kumar, Suresh Kumar, S.K. Sharma, D. Roy. Materials Today: Proceedings, 2 (9-A), 4563 (2015).

[33] W. Zhu, C. Wang, X. Li, M.S. Khan, X. Sun, H. Ma. Biosens. Bioelectron., 97, 115 (2017).

[34] M. Masab, M. Hanif, F. Shah, M. Yasir, H. Muhammad. Mater. Sci. Semicond. Process., 81, 113 (2018).
[35] M.A. Osman, A.G. Abd-Elrahim, A.A. Othman. Mater. Charact., 144, 247 (2018).

[36] S. Muruganandam, G. Anbalagan, G. Murugadoss. Indian J. Phys., 89 (8), 835 (2015).

[37] Nikita H. Patel, M.P. Deshpande, S.H. Chaki, H.R. Keharia. J. Mater. Sci. Mater. Electron., 28 (15), 10866 (2017).

[38] J. Planelles-Aragó, B. Julián-López, E. Cordoncillo, P. Escribano, F. Pellé, B. Viana, C. Sanchez. J. Mater. Chem., 18, 5193 (2008).

[39] Ю.Г. Галяметдинов, Д.О. Сагдеев, В.К. Воронкова, А.А. Суханов, Р.Р. Шамилов. Изв. АН. Сер. хим., 67 (1), 172 (2018).

[40] Д.О. Сагдеев, Р.Р. Шамилов, В.К. Воронкова, А.А. Суханов, Ю.Г. Галяметдинов. Вестн. Технологического ун-та, 21 (10), 21 (2018).

[41] Д.О. Сагдеев. Автореф. канд. дис. (Казань, КНИИТУ, 2019).

[42] В.Ф. Агекян. ФТТ, 44 (11), 1921 (2002).

[43] A.A. Bol, R. Van Beek, J. Ferwerda, A. Meijerink. J. Phys. Chem. Solids, 64 (2), 247 (2003).

[44] S. Salimian, S. Farjami Shayesteh. J. Supercond. Nov. Magn., 25 (6), 2009 (2012).

[45] А.А. Исаева, В.П. Смагин. Ползуновский вестн., 2, 107 (2018).

[46] M. Romcevic, N. Romcevic, R. Kostic, L. Klopotowski, W.D. Dobrowolski, J. Kossut, M.I. Čomor. J. Alloys Compd., 497 (1-2), 46 (2010).

[47] M. Kuzmanović, D.K. Bozanić, D. Milivojević, D.M. Ćulafić, S. Stanković, C. Ballesteros, J. Gonzalez-Benito. RSC Advances, 7 (84), 53422 (2017).

[48] В.П. Смагин, Д.А. Давыдов, Н.М. Унжакова, А.А. Бирюков. ЖНХ, 60 (12), 1734 (2015).

[49] В.П. Смагин, А.А. Исаева, Н.С. Еремина, А.А. Бирюков. ЖПХ, 88 (6), 924 (2015).

[50] В.П. Смагин, Н.С. Еремина, А.А. Исаева. ЖНХ, 62 (1), 130 (2017).

[51] А.А. Бирюков, Т.И. Изаак, В.А. Светличный, О.В. Бабкина. Изв. вузов. Физика, 49 (12), 81 (2006).

[52] S. Mohan, O.S. Oluwafemi, S.P. Songca, S.C. George, P. Miska, D. Rouxel, N. Kalarikkal, S. Thomas. Mater. Sci. Semicond. Process., 39, 587 (2015).

[53] K. Matras-Postolek, K. Chojnacka-Gorka, M. Bredol, K. Guguła. J. Luminesc., 203, 655 (2018).

[54] R.M. Abozaid, Z.Ž. Lazarević, I. Radović, M. Gilić, D. Šević, M.S. Rabasović, I. Radović. Optical Mater., 92, 405 (2019).

[55] А.А. Исаева, В.П. Смагин. ЖНХ, 64 (10), 1020 (2019).

[56] В.П. Смагин, Н.С. Еремина, Д.А. Давыдов, К.В. Назарова, Г.М. Мокроусов. Неорг. матер., 52 (6), 664 (2016).

[57] В.Г. Клюев, Т.Л. Майорова, М. Фам Тхи Хаи, В.Н. Семенов. Конденсированные среды и межфазные границы, $11(1), 58$ (2009).

[58] В.П. Смагин, Н.С. Еремина, М.С. Леонов. ФТП, 52 (8), 891 (2018).

[59] А.А. Исаева, В.П. Смагин. ФТП, 54 (5), 435 (2020).

[60] L. Brus. Quant. Electron, 22, 1909 (1986).

[61] Э.А. Романов. Автореф. канд. дис. (Ижевск, УдГУ, 2011).

[62] С.В. Ремпель, А.А. Разводов, М.С. Небогатиков, Е.В. Шишкина, В.Я. Шур, А.А. Ремпель. ФТТ, 55 (3), 567 (2013).

[63] В.П. Смагин, Н.С. Еремина, А.А. Исаева, Ю.В. Ляхова. Неорг. матер., 53 (3), 252 (2017).

Редактор Л.В. Шаронова 


\section{Synthesis and photoluminescence \\ of nanoscale structures based on zinc, cadmium and manganese sulfides in a polyacrylate matrix}

A.A. Isaeva, V.P. Smagin

Altai State University,

656049 Barnaul, Russia

Abstract Photoluminescence of nanoscale structures based on zinc, cadmium and manganese sulfides depending on the conditions of synthesis and doping in the medium (poly)methylmethacrylate (PMMA). Photoluminescence excitation is associated with interband transitions of electrons in the semiconductor structures, absorption of optical radiation energy by defects in the crystal structure, as well as with the transfer of energy to the excited energy levels of $\mathrm{Mn}^{2+}$ ions. Luminescence occurs as a result of recombination processes at the levels of defects in the structure of the surface of particles and ${ }^{4} T_{1} \rightarrow{ }^{6} A_{1}$ transitions between the proper energy levels of $\mathrm{Mn}^{2+}$ ions. Based on changes in the photoluminescence spectra and photoluminescence excitation of $\mathrm{PMMA} /(\mathrm{Zn}, \mathrm{Cd}, \mathrm{Mn}) \mathrm{S}$ compositions, assumptions are made about the structure of particles. It is shown that their photoluminescence is affected by the distribution of $\mathrm{Mn}^{2+}$ ions in the structure of layers and on the surface of particles. 